\title{
A Novel Improving Technology to Intelligent Controllers - A Typical Case Study for Turbine Speed Regulation of a Smart Hydropower Plant
}

\author{
Ngoc-Khoat Nguyen \\ Faculty of Control and Automation, Electric Power University, Hanoi, Vietnam \\ khoatnn@epu.edu.vn
}

\begin{abstract}
A novel method to further improve control quality of existing intelligent controllers applying fuzzy logic and artificial neural network techniques is presented in this study. The novel idea is that a number of meaningful scaling factors, which are determined by an effective optimization mechanism, will be embedded in the control system to fine-tune the dynamic responses, thereby further improve control performances. The proposed control strategy will be applied to a typical case study regarding the speed control problem of synchronous generators in a hydropower system affected by the random and continuous load changes. Numerical simulations implemented in MATLAB/Simulink package are used to completely verify the applicability and superiority of the proposed control scheme in comparison with the original counterparts and traditional regulators using PID.
\end{abstract}

Key words: FL, ANN-based NARMA, scaling factors, turbine speed control.

\section{INTRODUCTION}

There seems to be no compelling reason to argue that one of the most effective methods to design a successful control strategy is to improve control performances of existing controllers. This is not only applied for the conventional regulators such as PID which stands for Proportional-Integral-Derivative, but it is also able to be applied for the intelligent controllers using modern techniques i.e. fuzzy logic (FL) and artificial neural network (ANN). This is highly meaningful to seek a novel method to further enhance control performances of the modern control systems.

The FL technique-based controllers which operate depending upon experiences of experts consist of several crucial components: I/O membership functions for fuzzification and defuzzification, a rule base and an inference engine. A lot of control systems applying the FL-based controllers obtained good control performances [1-9]. However, there is an issue which can strongly affect the control quality of the system. This is the determination of scaling factors for a PD- or PI-type FL controllers which are two most effective types of the FL-based controllers. If these factors can be tuned successfully by an effective optimization mechanism, the control quality of the system is able to be further improved. Such a principle has been reported in literature [1-4].

Similar to the FL-based controllers, ANN-based control strategies considered to be intelligent controllers have been recently used for complex control systems [1, 9-10]. These controllers are highly suitable for nonlinear control systems in nature. Technically, a neural network is a set of artificial neurons should learn the plant at first. Then, such a network can be used for the design of a controller. It is the fact that there are various ANN - based models applied for designing intelligent controllers. In the library of Simulink, there are three typical types of the ANN-based controllers including nonlinear autoregressive moving average (NARMA), model reference adaptive controller (MRAC) and model predictive control (MPC). Among them, the NARMA model has been applied for a lot of control problems with good control performances [10]. When going deeper into such a NARMA architecture, it should be affirmed that its control quality can be further improved. The idea may also refer to the foresaid FL-based controller by means of adding a meaningful scaling factor behind the ANN model. Such a coefficient is also determined by using an effective optimization method.

This paper is organized as follows. First, the typical structures of FL and ANN-based control strategies will be presented in Section 2 as an overview. Then, we focus on modified procedures presented in Section $\mathbf{3}$ to design improved intelligent control strategies including FL-based and NARMA controllers. In these novel modified controllers, several meaningful gains which are determined by the PSO standing for particle swarm optimization algorithm will be embedded. To demonstrate the applicability and superiority of the proposed control architectures, Section $\mathbf{4}$ then introduces a typical case study of a hydropower plant in dealing with the turbine speed control against continuous and random load variations. At last, Section 5 will provide conclusion and future word raised from this study. 
Ngoc-Khoat Nguyen, International Journal of Emerging Trends in Engineering Research, 8(6), June 2020, 2388 - 2394

\section{TYPICALLY INTELLIGENT CONTROLLERS APPLYING FUZZY LOGIC AND ARTIFICIAL NEURAL NETWORK TECHNIQUES}

A typical simple control system includes a control plant, a controller and a sensor. If the controller is designed as an intelligent one, such a control system should be defined as an intelligent control strategy. The term "intelligent control" implies a control technique applying human knowledge-decision making. This means that such a control technique uses human intelligence which is technically so-called experience of experts to intervene in the working principle of the system in order to achieve desired control performances [1-2]. A typical intelligent control strategy is shown in Figure 1 (a).

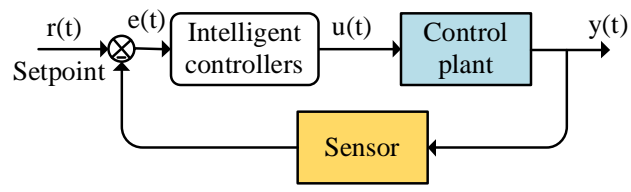

(a)

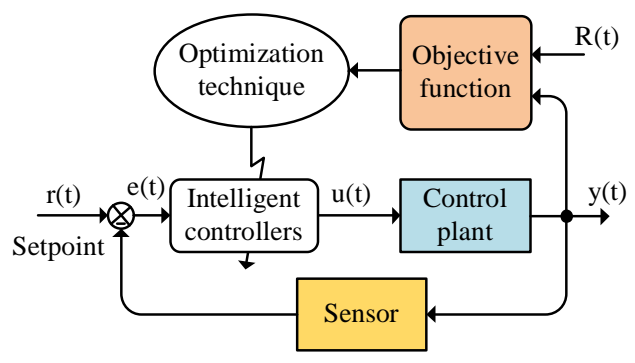

(b)

Figure 1: Control strategies applying intelligent controllers.

(a) Conventional control architecture

(b) Improved control architecture

The intelligent controllers have been found depending upon several techniques, such as artificial neural network, fuzzy logic and metaheuristic mechanisms. The integration between them as shown in Figure 1(b) is presented below to design an effective control strategy.

\section{IMPROVED INTELLIGENT CONTROLLERS}

\subsection{Improved FL controllers}

A controller applying fuzzy logic technique is one of the most typical cases of the intelligent control. This type of intelligent controllers operates relying on the fuzzy logic inference which normally includes four major phases [1-3]:

(1) Fuzzification is the first stage used to convert crisp quantities into fuzzy quantities.

(2) Rule base or knowledge base is represented by IF-THEN rules describing the experiences of experts to the control problem which is under the consideration.

(3) Inference mechanism, considered to be the heart of the FL architecture, executes the reasoning to make human decisions regarding the considering control process.

(4) Defuzification is considered to be the inverse stage of the fuzzification. Technically, this is used to convert the fuzzy results into the crisp results.

When applying a typical FL-based control strategy, it is necessary to consider three important components: membership functions, rule base and scaling factors. With a PD or PI-type FL controller as mentioned in [1], when the membership functions as well as the rule base are selected in a standard method, the vital mission to further improve control quality is to determine three scaling factors: two for the inputs and one for the output of the FL model. The illustration is shown in Figure 2(a) which is developed from the principle indicated in Figure 1(b). Here, three scaling factors include $K_{1}, K_{2}$ and $K_{3}$. The first two factors are for the two inputs error $e(t)$ and derivative of $e(t)$. The last one is for the output $u(t)$ which means the control signal created from the FL controller. It should be clear optimization of these factors are able to obtain the better control performances which will be demonstrated in the next section of this study.

\subsection{Improved ANN-based NARMA}

Similar to the FL-based control strategy, the ANN-based controllers have become the effective approaches of the intelligent control. One of the most typical control schemes is presented in Figure 2(b). The ANN-based controller applied for the control system is the NARMA-L2 [9, 10]. The working principle of this control architecture following two steps below:

(i) Step 1: Identification. The idea of this control strategy is based on the linearization feedback in which the control plant needs to be linearized first by an identification process. A neural network may need to be used for such an identification.

(ii) Step 2: Design of ANN-based controller. After the identification process as mentioned above, an ANN-based controller can be built following the idea of model reference tracking control. The controller will be designed in minimizing the error between the reference model and the approximated model obtained in the foresaid identification stage.

Following the idea of the FL-based controller, to further enhance the control quality of the ANN-based NARMA controller, the optimization technique will also be applied. As shown in Figure 2(b), only one factor $K_{N}$ is embedded in the control topology and it is successfully determined by an effective optimization mechanism, i.e. PSO. The applicability of the proposed ANN-based control architecture together with the FL-based controllers will be demonstrated in the next section. 


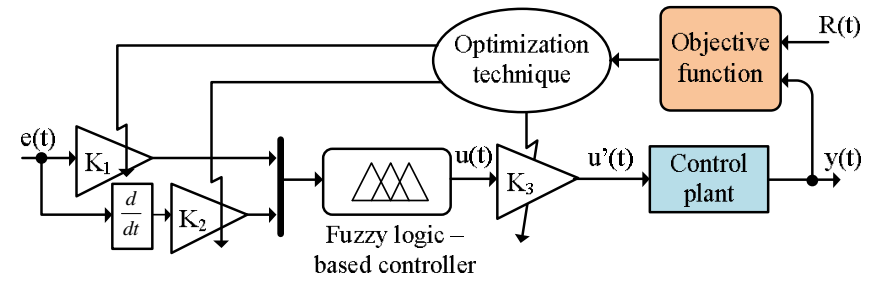

(a)

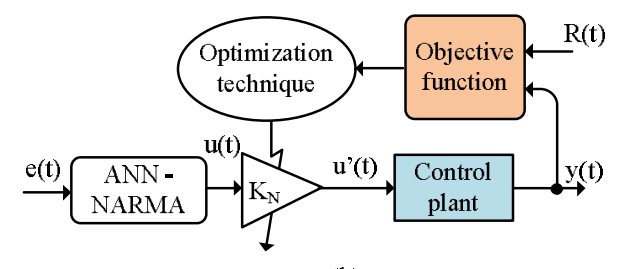

(b)

Figure 2: Control strategies applying improved intelligent controllers

(a) ANN-based NARMA model

(b) FL - based controller

\section{A TYPICAL CASE STUDY TO VERIFY THE EFFECTIVENESS OF THE PROPOSED CONTROL STRATEGIES}

This section is to present a case study regarding the speed control of synchronous generators in a hydropower plant. This is one of the most crucial control problems of the hydropower plant in order to maintain the system frequency, ensuring the stability of the power plant. To apprehend the applicability of the proposed intelligent controllers as presented in the previous sections, it should be necessary to establish the mathematical model of a hydropower plant regarding the speed control problem.

\subsection{Mathematical model of the hydropower plant}

A hydropower plant typically comprises of essential components such as a reservoir with dams, penstocks, hydraulic turbine, speed governors including pilot actuators and servo motors, and synchronous generators. Each generator in such a power facility is always equipped with a governor characterized by a regulation coefficient $R$ to govern the speed of the generator as the first phase. This is able to define as the primary control loop. The three crucial components, namely the speed governor, the penstock-turbine and the generator-load, are mathematically modeled by transfer functions in the frequency domain as shown in Figure 3 [11].

- The pilot actuator:

$$
\frac{\Delta X_{e}(s)}{E(s)}=\frac{1}{1+T_{P} . s}
$$

$$
\text { Where } E(s)=-U(s)-\frac{1}{R} \Delta \Omega(s)
$$

Substitute (2) to (1) and convert the result into time domain, one can be obtained as follows:

$$
\Delta \dot{x}_{e}(t)=-\frac{1}{T_{P}} \Delta x_{e}(t)-\frac{1}{R T_{P}} \Delta \omega(t)-\frac{1}{T_{P}} u(t)
$$

Similarly, after converting the transfer functions of the remaining components, the following can be achieved:

- The servo motor:

$$
\Delta \dot{g}(t)=\frac{1}{T_{g}} \Delta x_{e}(t)-\frac{1}{T_{g}} \Delta g(t)
$$

- The penstock and hydraulic turbine:

$$
\Delta \dot{P}_{m}(t)=-\frac{2}{T_{g}} \Delta x_{e}(t)+\left(\frac{2}{T_{\mathrm{w}}}+\frac{2}{T_{g}}\right) \Delta g(t)-\frac{2}{T_{\mathrm{w}}} \Delta P_{m}(t)
$$

- The generator-load model:

$$
\Delta \dot{\omega}(t)=\frac{1}{M} \Delta P_{m}(t)-\frac{D}{M} \Delta \omega(t)-\frac{1}{M} \Delta P_{L}(t)
$$

It is straightforward to deduce the following state-space model from equations (3)-(6) as presented below:

$$
\underline{\dot{x}}(t)=A \cdot \underline{x}(t)+B \cdot u(t)+F \cdot \Delta P_{L}(t)
$$

Where the state vector $\underline{x}(t)$ and corresponding matrices $A, B, C$ are defined as follows:

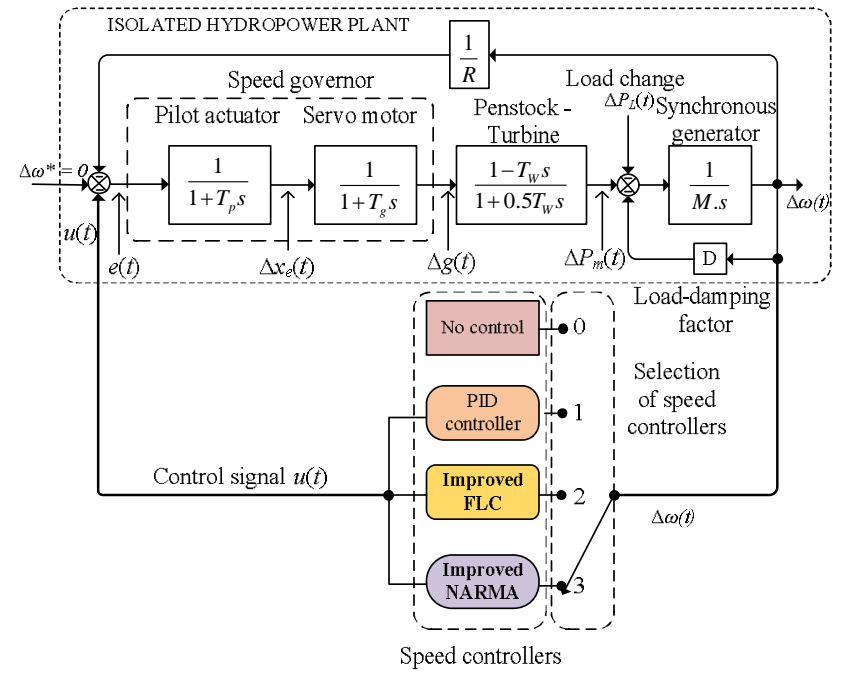

Figure 3: A typical-isolated hydropower plant applying different speed controllers

$$
\begin{gathered}
\underline{x}(t)=\left[\begin{array}{c}
\Delta x_{e}(t) \\
\Delta g(t) \\
\Delta P_{m}(t) \\
\Delta \omega(t)
\end{array}\right] \\
\left.A \begin{array}{ccccc}
0 & -\frac{1}{T_{P}} & 0 & 0 & -\frac{1}{T_{p} R} \\
0 & \frac{1}{T_{p}} & -\frac{1}{T_{p}} & 0 & 0 \\
0 & -\frac{2}{T_{g}} & \left(\frac{2}{T_{\mathrm{w}}}+\frac{2}{T_{g}}\right) & -\frac{2}{T_{\mathrm{w}}} & 0 \\
0 & 0 & 0 & \frac{1}{M} & -\frac{D}{M}
\end{array}\right] ;
\end{gathered}
$$


Ngoc-Khoat Nguyen, International Journal of Emerging Trends in Engineering Research, 8(6), June 2020, 2388 - 2394

$$
B=\left[\begin{array}{c}
-\frac{1}{T_{p}} \\
0 \\
0 \\
0
\end{array}\right] \text { and } F=\left[\begin{array}{c}
0 \\
0 \\
0 \\
-\frac{1}{M}
\end{array}\right]
$$

\subsection{Numerical simulations to testify the proposed control methodologies}

Simulation processes using an effective simulation tool as MATLAB play an important role in verification of feasibility of the proposed controllers. This section is executed following several steps below:

- Design the simulation model in MATLAB/Simulink environment corresponding to Figure 3 shown earlier. It is noted that the simulation parameters are given in [11]. - Apply three controllers, namely PID, FL- and NARMA -based speed control strategies together with the no-control case in two scenarios of load changes $\Delta P_{L}(t)$ as presented in Figures 8-10. The intelligent controllers should be investigated in two perspectives: with and without using the optimization mechanism. In this paper, the PSO, one of the most effective optimization methods, is applied for the improved intelligent speed controllers [13-17]. The objective or fitness function used for such a PSO technique is:

$$
f_{\text {fitness }}=\int_{0}^{T}|\Delta \omega(t)| t d t \rightarrow \min
$$

Where $T$ denotes the simulation time. In this study, simulation parameters for the PSO are shown in Table 1.

- Simulation results are evaluated by a comparison of dynamic responses regarding each controller.

The NARMA controller with simulation parameters and training processes are shown in Figures 4-5. The convergences of the PSO applied for the improved FL and NARMA speed controllers are depicted in Figure 7(a) and Figure 7(b). Specifically, three factors of the FL-based intelligent controller which are determined by the PSO mechanism are numerically presented in Table 2 . It is clear the PSO technique applied for both intelligent controllers is completely converged, ensuring the high control quality of the proposed controllers. Simulation results regarding three speed controllers presented in Figures 8-12 for two scenarios of load changes obviously present much better control performances of the proposed intelligent controllers. Especially, when compared with the initial FL and NARMA controllers, the dynamics of the proposed ones are also better as shown in Figures 11-12 (c, d). They are absolutely able to verify the high applicability of the proposed control strategies when conducting the speed maintenance of the synchronous generator against load changes in a hydropower system.
Table 1: Parameters for executing the PSO algorithm

\begin{tabular}{|l|l|l|}
\hline Controller & $\begin{array}{l}\text { Number of } \\
\text { variables }\end{array}$ & $\begin{array}{l}\text { Iteratio } \\
\text { ns }\end{array}$ \\
\hline NARMA & 1 & 30 \\
\hline $\begin{array}{l}\text { Fuzzy logic } \\
\text { controller }\end{array}$ & 3 & 50 \\
\hline
\end{tabular}

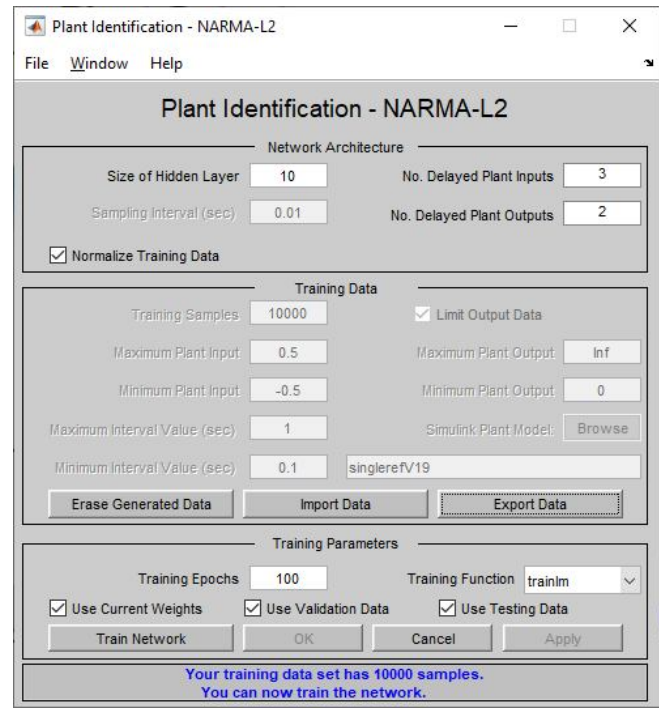

Figure 4: Simulation parameters of the NARMA model
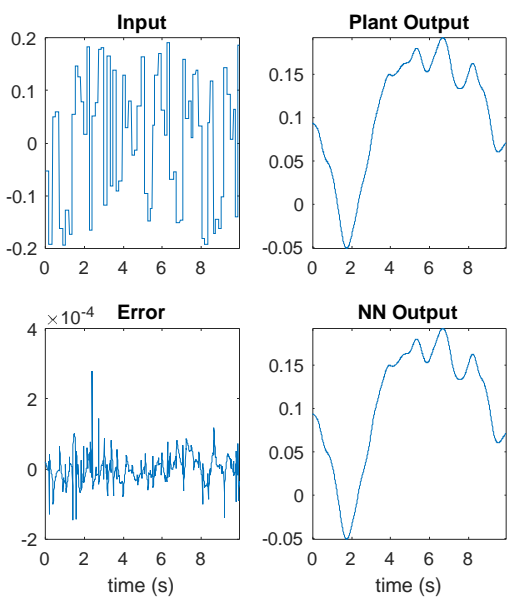

Figure 5: Training data of the NARMA model

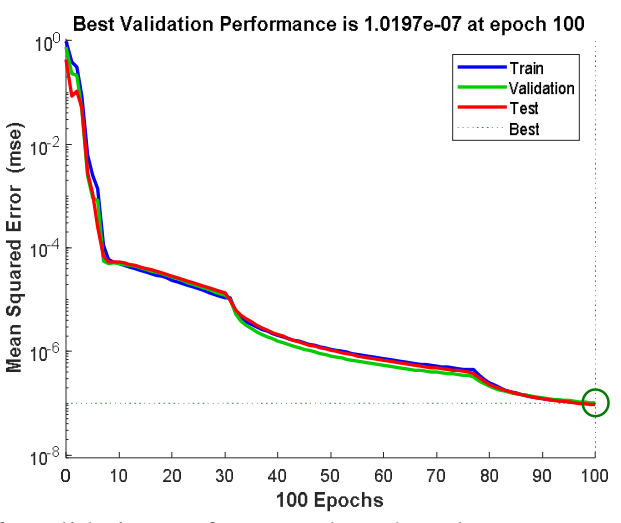

Figure 6: Validation performance based on the mean squared error. 


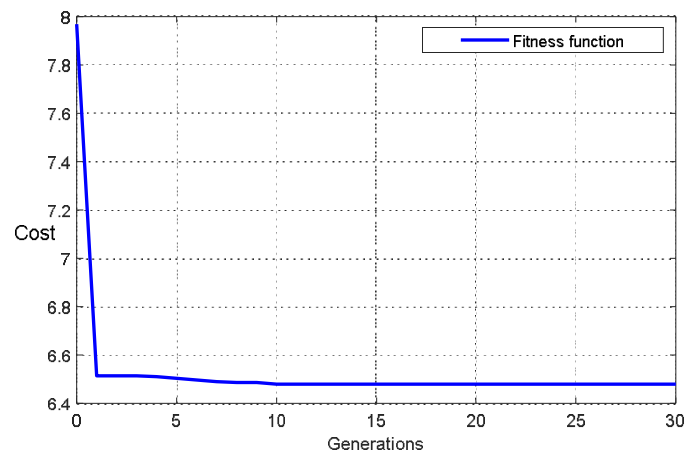

(a)

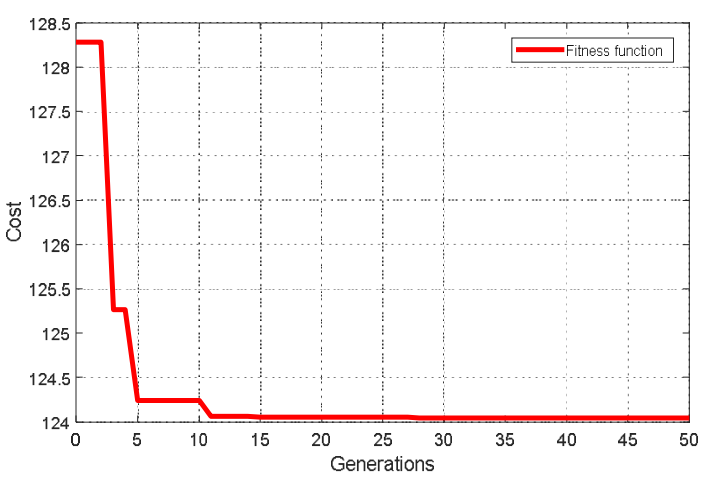

(b)

Figure 7: PSO convergences

(a) For the FL-based controller

(b) For the NARMA-based controller

Table 2: Convergences of PSO algorithm applied for the FL-based controller (cont)

\begin{tabular}{|l|l|l|l|l|}
\hline No & $\boldsymbol{K 1}$ & $\boldsymbol{K 2}$ & $\boldsymbol{K 3}$ & Cost \\
\hline \multirow{2}{*}{1} & & 0.99412 & 0.72821 & 6.51461 \\
& 1 & 8 & 9 & 7 \\
\hline \multirow{2}{*}{2} & & 0.99412 & 0.72821 & 6.51461 \\
& 1 & 8 & 9 & 7 \\
\hline \multirow{2}{*}{3} & & 0.99412 & 0.72821 & 6.51461 \\
& 1 & 8 & 9 & 7 \\
\hline \multirow{2}{*}{4} & \multirow{2}{*}{1} & 1 & 0.72883 & 6.51101 \\
& 1 & & 0.71074 & 6.50512 \\
\hline \multirow{2}{*}{5} & & 1 & 8 & 7 \\
\hline \multirow{2}{*}{$\ldots$} & 1 & $\ldots$ & $\ldots$ & $\ldots$ \\
\hline \multirow{2}{*}{28} & 0.89661 & 0.96606 & 0.81662 & 6.47893 \\
& 2 & 3 & 5 & 3 \\
\hline \multirow{2}{*}{29} & 0.89661 & 0.96606 & 0.81662 & 6.47893 \\
& 2 & 3 & 5 & 3 \\
\hline \multirow{2}{*}{30} & 0.89661 & 0.96606 & 0.81662 & 6.47893 \\
& 2 & 3 & 5 & 3 \\
\hline
\end{tabular}

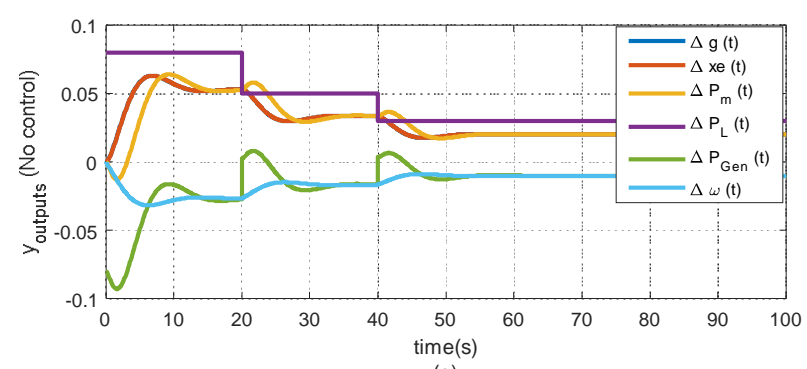

(a)

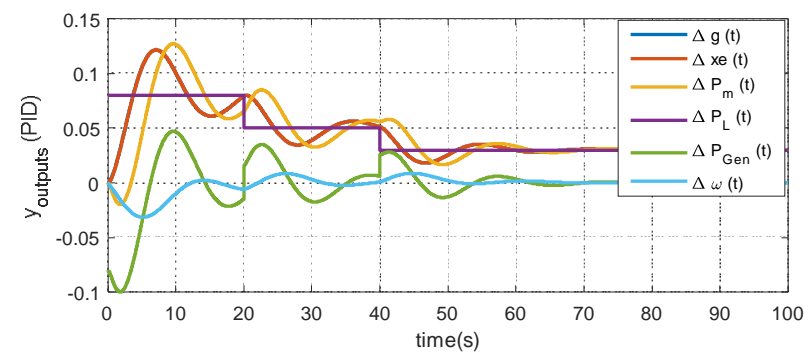

(b)

Figure 8: Simulation results for no control and PID - case 1

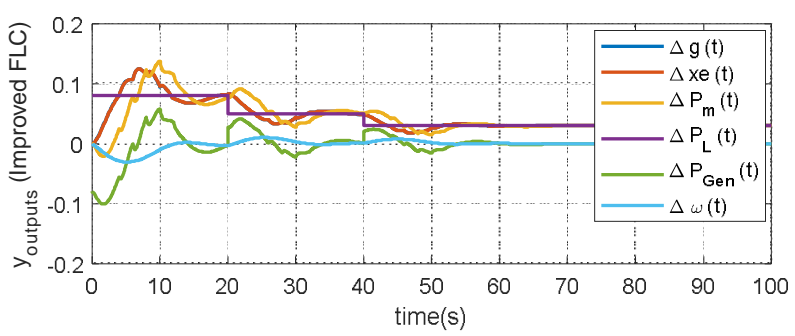

(a)

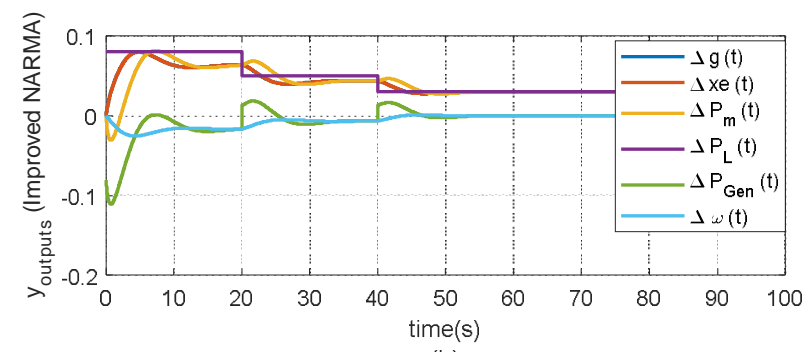

(b)

Figure 9: Simulation results of the FL and NARMA controllers case 1 


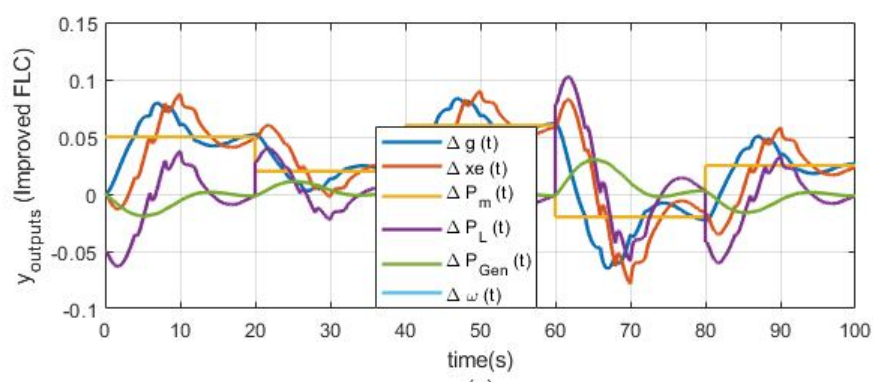

(a)

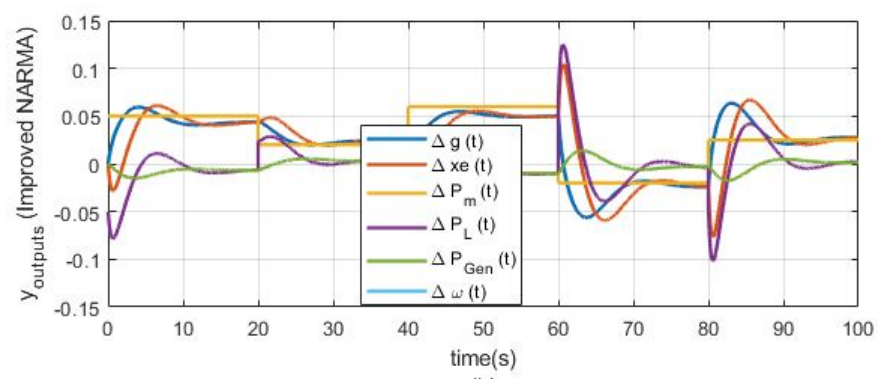

(b)

Figure 10: Simulation results for the FL and NARMA controllers case 2

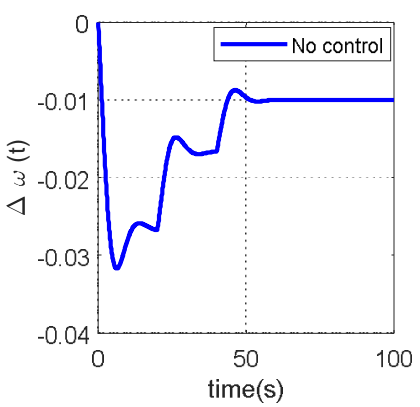

(a)

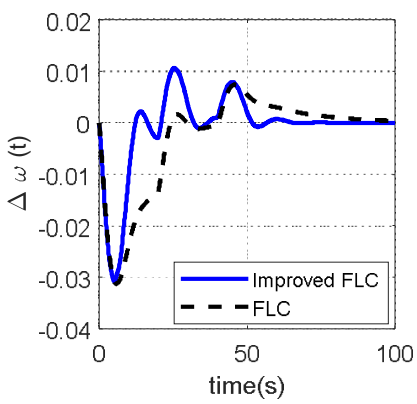

(c)

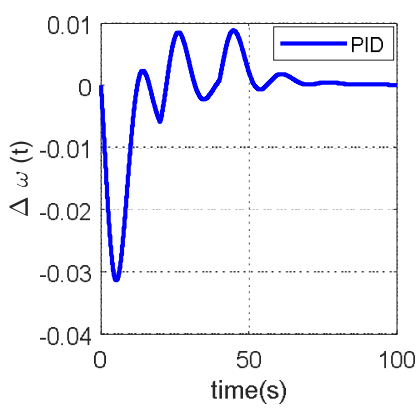

(b)

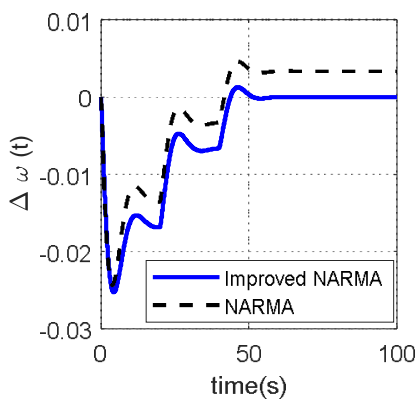

(d)
Figure 11: Comparison of three controllers - case 1

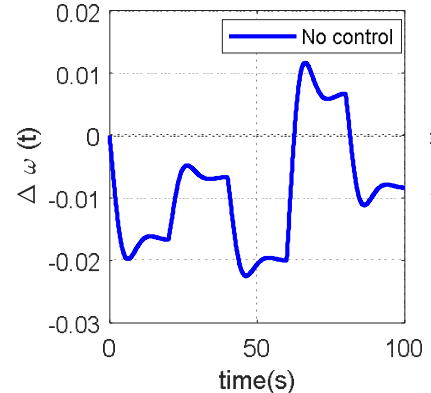

(a)

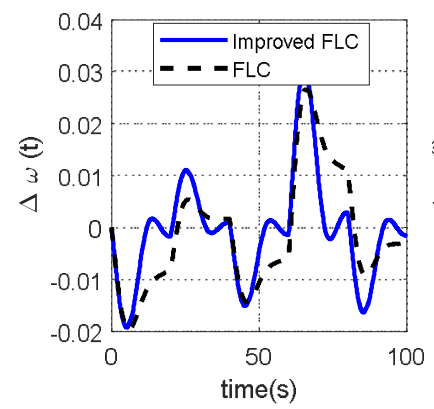

(c)

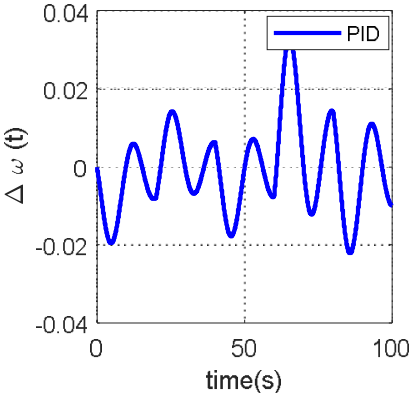

(b)

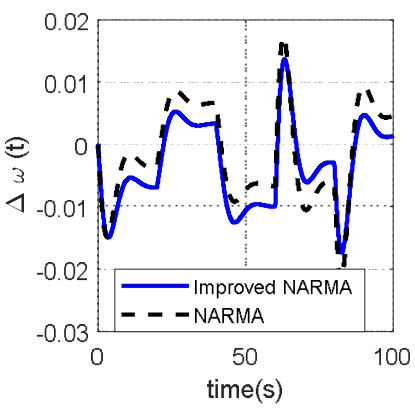

(d)
Figure 12: Comparison of three controllers - case 2

\section{CONCLUSION AND FUTURE WORK}

The current paper proposed a novel modification to further enhance the control performances of two intelligent control strategies, namely FL and NARMA controllers. With a number of meaningful factors successfully determined by the PSO algorithm are embedded in the control architectures, the control performances able to be further improved. When applied to a hydropower system in dealing with the speed control problem against random load changes which is considered to be a typical case study, the proposed controllers obtained much better control performances in comparison with those of the other controllers. This has obviously demonstrated the applicability of the intelligent control strategies proposed in this study.

Future work raising from this study is the focus on further extending applications of the proposed control strategies, especially applications of practical control systems. This absolutely concerns the complexity as well as the size of the control systems. For instance, large power systems with nonlinear and uncertain characteristics should be the potential candidates which are able to apply the proposed intelligent control strategies in the near future.

\section{ACKNOWLEDGEMENT}

The author wishes to thank Dr. Dao Thi Mai Phuong from Hanoi University of Industry for her meaningful discussion on the theory of the bio-inspired optimization techniques. 


\section{REFERENCES}

1. B. K. Bose. Power electronics and motor drives: advances and trends. Elsevier, 2010.

2. Y. John et al. Industrial applications of fuzzy logic and intelligent systems. Springer, 1995.

3. A. Don M. Africa et al. Fuzzy logic temperature control: A feedback control system implemented by fuzzy logic, International Journal of Emerging Trends in Engineering Research, Vol. 8, No. 5, pp. 1879-1885, 2020.

https://doi.org/10.30534/ijeter/2020/66852020

4. İlhan Kocaarslan, Ertuğrul Çam. Fuzzy logic controller in interconnected electrical power systems for load-frequency control, International Journal of Electrical Power \& Energy Systems, Vol. 27, Iss. 8, pp. 542-549, 2005.

https://doi.org/10.1016/j.ijepes.2005.06.003

5. R. Dhanalakshmi and S. Palaniswami. Application of multi stage fuzzy logic control for Load Frequency Control of an isolated wind diesel hybrid power system, International Conference on Green technology and environmental Conservation (GTEC-2011), Chennai, 2011, pp. 309-315, doi: 10.1109/GTEC.2011.6167685.

6. Umrao R., Chaturvedi D.K., Malik O.P. Load Frequency Control: A Polar Fuzzy Approach. In: Panigrahi B.K., Suganthan P.N., Das S., Satapathy S.C. (eds) Swarm, Evolutionary, and Memetic Computing. SEMCCO 2011. Lecture Notes in Computer Science, vol 7076. Springer, Berlin, Heidelberg, 2011.

https://doi.org/10.1007/978-3-642-27172-4_60

7. Ertuğrul Çam. Application of fuzzy logic for load frequency control of hydroelectrical power plants, Energy Conversion and Management, Vol. 48, Iss. 4, pp. 1281-1288, 2007.

8. Hussein, T.; Shamekh, A. Design of PI Fuzzy Logic Gain Scheduling Load Frequency Control in Two-Area Power Systems. Designs, 3, 26, pp. 1-11, 2019. https://doi.org/10.3390/designs3020026

9. N.K. Nguyen, Q. Huang, T.M.P. Dao. An Investigation of Intelligent Controllers Based on Fuzzy Logic and Artificial Neural Network for Power System Frequency Maintenance, Turkish Journal of Electrical Engineering \& Computer Sciences, vol. 24(4), pp. 2893-2909, 2016.

10. K. Uçak, G. Öke Günel. A novel adaptive NARMA-L2 controller based on online support vector regression for nonlinear systems, Neural Process Lett, Vol. 44, pp. 857-886, 2016.

11. P. Kundur. Power system stability and control, McGraw - Hill Education - Europe, 2015.

12. Sun, J., Lai, C.H., Wu, X.J. Particle Swarm Optimisation. Boca Raton: CRC Press, 2012.
13. N. Mo, Z. Y. Zou, K. W. Chan, T. Y. G. Pong. Transient stability constrained optimal power flow using particle swarm optimization, IET Generation, Transmission \& Distribution, Vol. 1, No. 3, pp. 476-483, 2007. https://doi.org/10.1049/iet-gtd:20060273

14. Zafer Bingül, Oğuzhan Karahan. A Fuzzy Logic Controller tuned with PSO for 2 DOF robot trajectory control, Expert Systems with Applications, Vol. 38, Iss. 1, pp. 1017-1031, 2011.

15. Oscar Castillo, Ricardo Martínez-Marroquín \& Patricia Melin. Bio-inspired Optimization of Fuzzy Logic Controllers for Robotic Autonomous Systems with PSO and ACO. Fuzzy Information and Engineering, 2:2, 119-143, 2010. https://doi.org/10.1007/s12543-010-0044-7

16. David Aregovich Petrosov et al. Application of Artificial Neural Networks in Genetic Algorithm Control Problems. International Journal of Emerging Trends in Engineering Research, Vol. 8, No. 2, pp. 177-181, 2020. https://doi.org/10.30534/ijeter/2020/24812020

17. Omdev Dahiya, Kamna Solanki, Sandeep Dalal, Amita Dhankhar. An Exploratory Retrospective Assessment on the Usage of Bio- inspired Computing Algorithms for Optimization. International Journal of Emerging Trends in Engineering Research, Vol. 8, No. 2, pp. 414-434, 2020. https://doi.org/10.30534/ijeter/2020/29822020 